\title{
Educacạ̃o intercultural no Brasil: a perspectiva epistemológica da complexidade
}

Reinaldo Matias Fleuri

Palavras-chave: educação

intercultural; pluridade

cultural; identidade;

transversalidade;

epistemologia; complexidade.

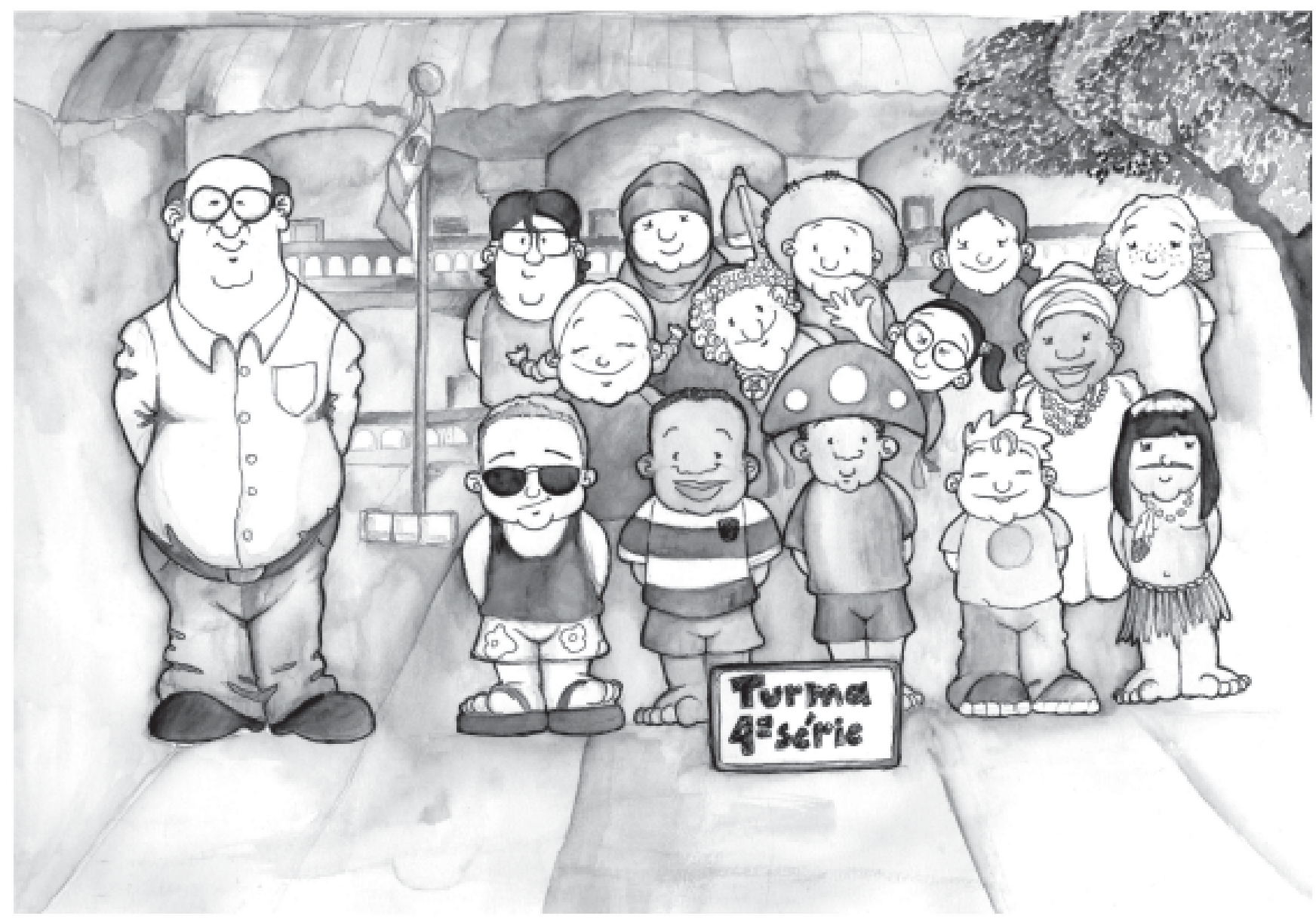

A contexto das lutas sociais contra

globalização econômica, propõe o contexto das lutas sociais contra os processos crescentes de exclusão social inerentes à desenvolvimento de estratégias que promovam a construção de identidades particulares e o 
reconhecimento das diferenças ao mesmo tempo que sustentem a inter-relação crítica e solidária entre diferentes grupos. $\mathrm{O}$ artigo apresenta uma conceituação operacional de educação intercultural, elaborada a partir dos estudos desenvolvidos na Europa. Verifica a necessidade de se recolocar a proposta de educação intercultural, considerando a especificidade da formação das identidades culturais e dos processos de integração interétnica no Brasil. É propõe uma perspectiva epistemológica da complexidade, com base nas premissas de Gregory Bateson, para compreender e para orientar o desenvolvimento de contextos educativos que promovam a articulação entre diferentes contextos subjetivos, sociais e culturais.

\section{Introdução}

Com a globalização da economia mundial, as relações sociais tornam-se, no plano econômico e político, cada vez mais transnacionais e, no plano cultural, enfrentam o desafio da hibridação, da diversidade e do respeito à diferença. Juntamente com a defesa das identidades e da pertença étnica, ${ }^{1}$ surge então a necessidade de abertura ao outro e à reciprocidade, abrindo possibilidade de um movimento cidadão sob a forma de redes e parcerias, onde a complementaridade se constrói a partir do respeito às diferenças.
O quadro de complexidade das relações sociais e culturais no mundo contemporâneo requer novas orientações epistemológicas no campo da pesquisa e da educação. É o que emerge no debate entre o monoculturalismo e o multiculturalismo. De um lado, a visão essencialista, universalista, igualitária do monoculturalismo corre o risco de legitimar a dominação de um projeto civilizatório ante as minorias culturais. De outro lado o multiculturalismo, ao enfatizar a historicidade e o relativismo inerentes à construção das identidades culturais, permite pensar alternativas para as minorias; mas também pode justificar a fragmentação ou criação de guetos culturais que reproduzem desigualdades e discriminações sociais. Para além da redutiva oposição entre o monoculturalismo e o multiculturalismo, surge a perspectiva da educação intercultural. No contexto das lutas sociais contra os processos crescentes de exclusão econômico-política, a educação intercultural propõe, em nível das práticas educacionais, o desenvolvimento de estratégias que promovam a construção de identidades particulares e o reconhecimento das diferenças, ao mesmo tempo que sustentem sua inter-relação crítica e solidária (Scherer-Warren, 1998, p. 31-32).

Nesta perspectiva, a preocupação por uma educação que respeite a diversidade cultural emergiu de modo original na América Latina. Especialmente a partir dos anos cinqüenta, os movimentos de "cultura popular" - e que posteriormente vieram a ser denominados de "educação popular" - contribuíram significativamente para promover processos educativos a partir dos componentes culturais dos diversos grupos populares.

Entretanto, os estudos que se vêm recentemente elaborando nas diferentes áreas de saber sobre as relações multiculturais e interculturais trazem contribuições para se repensar as práticas educativas sob novas perspectivas. Neste artigo, pretendemos retomar parte da reflexão européia sobre a educação intercultural para, comparando com o contexto histórico, social e cultural brasileiro, apontar para a necessidade de uma perspectiva epistemológica capaz de entender e de elaborar a complexidade das relações interculturais na educação.

\footnotetext{
1 A pertença étnica implica um laço especial entre pessoas de origem comum e, ao mesmo tempo, a contraposição a pessoas de origem diferente da própria (Bonacich, Modell, 1980). Pertencer a um grupo significa compartilhar elementos comuns com outros membros e diferenciar-se em relação a outros grupos. Daí resulta o duplo significado da pertença para o indivíduo. Do ponto de vista da semelhança, a pertença é um pressuposto para a identificação do indivíduo. Ou seja, a afinidade que o indivíduo sente em relação a outros o leva a perceber-se como incluído em um contexto grupal, sendo impelido a utilizar o sujeito "nós", no lugar do "eu". Já do ponto de vista da diferença. a pertença torna-se critério de identidade do indivíduo. "Identidade significa a capacidade de estabelecer uma diferença observável entre si e o outro, de se diferenciar em relação ao mundo e de manter no decorrer do tempo a consciência de tal diferença" (Gallino, 1982, p. 145). Assim, semelhança e diferença são duas dimensões do conceito de pertença, que inclui, por um lado, o processo de identificação do indivíduo pelas suas afinidades com um grupo e, por outro lado, a afirmação de sua identidade,pela evidenciação das suas diferenças em relação aos outros.
} 


\section{Educação intercultural: uma conceituação operacional}

Um documento da Unesco, a Declaração sobre raça e sobre preconceitos raciais, de 1978, foi um dos primeiros textos a propor os conceitos fundantes da educação intercultural. A Declaração afirma que "todos os povos e todos os grupos humanos, qualquer que seja a sua composição ou a sua origem étnica, contribuem conforme a sua própria índole para o progresso das civilizações e das culturas, que, na sua pluralidade e em virtude de sua interpretação, constituem o patrimônio comum da humanidade"; enfatiza que

o processo de descolonização e outras transformações históricas conduziram a maioria dos povos precedentemente dominados a recuperar sua soberania, de modo a fazer com que a comunidade internacional seja um conjunto universal e ao mesmo tempo diversificado; reconhece, enfim, "o direito de todos os grupos humanos à identidade cultural e ao desenvolvimento da sua própria vida cultural no contexto nacional e internacional" (Unesco, 1978, apud Nanni, 1998, p. 12).

O reconhecimento da diversidade cultural admite diferentes enfoques.

Assim, os termos multi ou pluricultural indicam uma situação em que grupos culturais diferentes coexistem um ao lado do outro sem necessariamente interagir entre si.

O termo transcultural faz referência a elementos culturais comuns, aos chamados "traços universais", aos "valores permanentes" nas diferentes culturas. Ou seja, a perspectiva transcultural identifica estruturas semelhantes de relação social ou de interpretação em culturas diferentes, sem que estas culturas interajam entre si.

Já a relação intercultural indica uma situação em que pessoas de culturas diferentes interagem, ou uma atividade que requer tal interação. A ênfase na relação intencional entre sujeitos de diferentes culturas constitui o traço característico da relação intercultural. $\mathrm{O}$ que pressupõe opções e ações deliberadas, particularmente no campo da educação.

Alguns autores distinguem, de modo particular, a perspectiva multicultural da perspectiva intercultural de educação. Tanto o multiculturalismo quanto o interculturalismo referem-se, ambos, aos processos históricos em que várias culturas entram em contato entre si e interagem. Mas a diferença entre o multiculturalismo e o interculturalismo encontra-se no modo de se conceber a relação entre estas diferentes culturas, particularmente na prática educativa.

A primeira distinção entre a proposta de educação multicultural e a de educação intercultural refere-se à "intencionalidade" que motiva a relação entre grupos culturais diferentes. A perspectiva multicultural reconhece as diferenças étnicas, culturais e religiosas entre grupos que coabitam no mesmo contexto. $O$ educador que assume uma perspectiva multicultural considera a diversidade cultural como um fato, do qual se toma consciência, procurando adaptar-lhe uma proposta educativa. Adaptar-se, neste sentido, significa limitar os danos sobre si e sobre os outros. Mas o educador passa da perspectiva multicultural à intercultural, quando constrói um projeto educativo intencional para promover a relação entre pessoas de culturas diferentes.

Uma perspectiva multicultural limita-se a considerar a coabitação das diferenças culturais como um processo histórico natural, espontâneo, do qual se pode tomar consciência para se adaptar a ele. Podese, ao invés, falar de interculturalidade quando consideramos não apenas o processo histórico de coexistência entre as diferentes culturas, mas também a proposta de mudança e de projetualidade (Nanni, 1998, p. 30).

A segunda distinção entre educação multicultural e educação intercultural se refere aos diferentes modos de se entender a relação entre culturas na prática educativa. Na perspectiva multicultural, entendese, de modo geral, as culturas diferentes como objetos de estudo, como matéria a ser aprendida. Ao contrário, na perspectiva intercultural os educadores e educandos não reduzem a outra cultura a um objeto de estudo a mais, mas a consideram como um modo próprio de um grupo social ver e interagir com a realidade. A relação entre culturas diferentes, entendidas como contextos complexos, produz confrontos entre visões de mundos diferentes. 
A interação com uma cultura diferente contribui para que uma pessoa ou um grupo modifique o seu horizonte de compreensão da realidade, uma vez que lhe possibilita compreender ou assumir pontos-devista ou lógicas diferentes de interpretação da realidade ou de relação social.

Uma terceira característica da educação intercultural refere-se à ênfase nos sujeitos da relação. Neste sentido, a educação intercultural desenvolve-se como relação entre pessoas de culturas diferentes. Não simplesmente entre "culturas" entendidas de modo abstrato. Valoriza-se prioritariamente os sujeitos que são os criadores e sustentadores das culturas. As culturas não existem abstratamente. São saberes de grupos e de pessoas históricas, das quais jamais podem ser completamente separáveis. As pessoas são formadas em contextos culturais determinados. Mas são as pessoas que fazem cultura. Neste sentido, a estratégia intercultural consiste antes de tudo em promover a relação entre as pessoas, enquanto membros de sociedades históricas, caracterizadas culturalmente de modo muito variado, nas quais são sujeitos ativos.

A educação intercultural apresenta-se, para Antonio Nanni (1998), como um processo, ou seja, um caminho aberto, complexo e multidimensional, pois envolve uma multiplicidade de fatores e de dimensões: a pessoa e o grupo social, a cultura e a religião, a língua e a alimentação, os preconceitos e as expectativas. A educação intercultural não se reduz a uma simples relação de conhecimento: trata-se da interação entre sujeitos. Isto significa troca e reciprocidade entre pessoas vivas, com rostos e nomes próprios, reconhecendo seus direitos e sua dignidade. Uma relação que vai além da dimensão individual dos sujeitos e envolve identidades culturais diferentes.

A educação intercultural se configura como uma pedagogia do encontro até suas últimas conseqüências, visando promover uma experiência profunda e complexa, em que o encontro/confronto de narrações diferentes configura uma ocasião de crescimento para o sujeito, uma experiência não superficial e incomum de conflito/ acolhimento. No processo ambivalente da relação intercultural, é totalmente imprevisível seu desdobramento ou resultado final. Trata-se de verificar se ocorre, ou não, a "transitividade cognitiva", ou seja, a interação cultural que produz efeitos na própria matriz cognitiva do sujeito; o que constitui uma particular oportunidade de crescimento da cultura pessoal de cada um, assim como de mudança das relações sociais, na perspectiva de mudar tudo aquilo que impede a construção de uma sociedade mais livre, mais justa e mais solidária.

Ainda conforme Antonio Nanni (1998), a realização destes objetivos exige ao menos três mudanças no sistema escolar:

1. A realização do princípio da igualdade de oportunidades. A educação intercultural requer que se trate nas instituições educativas os grupos populares não como cidadãos de segunda categoria, mas que se reconheça seu papel ativo na elaboração, escolha e atuação das estratégias educativas. Além disso, é preciso repensar as funções, os conteúdos e os métodos da escola, de modo a se superar o seu caráter monocultural.

2. A reelaboração dos livros didáticos, a adoção de técnicas e de instrumentos multimediais. A educação intercultural requer profundas transformações no modo de educar. A prática educativa é estimulada a se tornar sempre mais interdisciplinar e multimedial. De modo particular, dever-se-á utilizar as técnicas e as metodologias ativas, do jogo à dramatização. Mas principalmente os livros didáticos deverão sofrer profundas mudanças. Estes são escritos geralmente na perspectiva da cultura oficial e hegemônica, e não para alunos pertencentes a "muitas culturas", diferentes entre si, justamente no modo de interpretar fatos, eventos, modelos de comportamento, idéias, valores. E talvez sejam usados justamente por aqueles alunos cujas culturas são representadas e julgadas, a partir da cultura hegemônica, de modo preconceituoso e discriminatório.

3. A formação e a requalificação dos educadores são talvez o problema decisivo, do qual depende o sucesso ou o fracasso da proposta intercultural. O que está em jogo na formação dos educadores é a superação da perspectiva monocultural e etnocêntrica que configura os modos tradicionais e consolidados de educar, a mentalidade pessoal, os modos de se 
relacionar com os outros, de atuar nas situações concretas.

Em suma, a educação intercultural pode ser definida operacionalmente, como

um processo multidimensional, de interação entre sujeitos de identidades culturais diferentes. Estes, através do encontro intercultural, vivem uma experiência profunda e complexa de conflito/ acolhimento. É uma oportunidade de crescimento da cultura pessoal de cada um, na perspectiva de mudar estruturas e relações que impedem a construção de uma nova convivência civil. A educação intercultural promove inclusive a mudança do sistema escolar: defende a igualdade de oportunidades educacionais para todos, requer a formação dos educadores, estimula a reelaboração dos livros didáticos, assim como a adoção de técnicas e de instrumentos multimediais (Nanni, 1998, p. 50).

Esta concepção indica que a educação intercultural ultrapassa a perspectiva multicultural, a qual reconhece o valor intrínseco de cada cultura e defende o respeito mútuo entre diferentes grupos identitários. Além disso, a educação intercultural se propõe construir uma relação recíproca entre eles, que se dá, não abstratamente, mas entre pessoas concretas, entre sujeitos que decidem construir contextos e processos de aproximação, de conhecimento recíproco e de interação. Essas relações produzem mudanças em cada indivíduo, favorecendo a consciência de si e reforçando a própria identidade. Sobretudo, promovem mudanças estruturais nas relações entre grupos. Estereótipos e preconceitos legitimadores de relações de sujeição ou de exclusão - são questionados, e até mesmo superados, à medida que sujeitos diferentes se reconhecem a partir de seus contextos, de suas histórias e de suas opções. A perspectiva intercultural de educação, enfim, implica mudanças profundas na prática educativa, de modo particular na escola, pela necessidade de oferecer oportunidades educativas a todos, respeitando e integrando a diversidade de sujeitos e de seus pontos-de-vista, bem como, pela necessidade de desenvolver processos educativos, metodologias e instrumentos pedagógicos que dêem conta da complexidade das relações humanas entre indivíduos e culturas diferentes. E, também, pela necessidade de reinventar o papel e o processo de formação dos educadores.

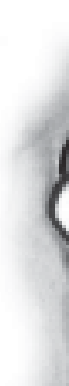
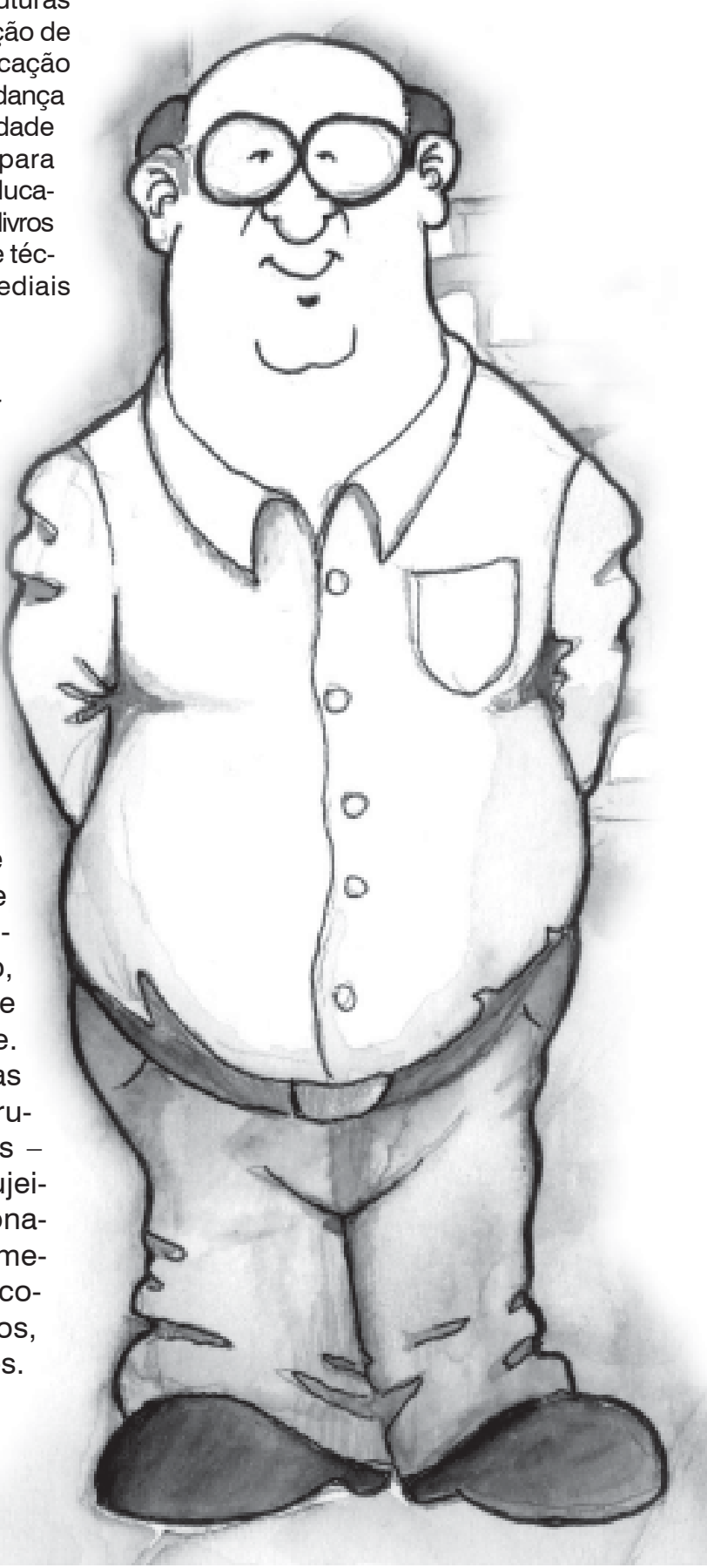


\section{0 desafio da educação intercultural no Brasil}

A relevância da educação intercultural evidencia-se, no sistema educacional brasileiro, quando os parâmetros curriculares nacionais para a educação fundamental no Brasil elegem a pluralidade cultural como um dos temas curriculares transversais, "por envolverem problemáticas sociais atuais e urgentes, consideradas de abrangência nacional e até mesmo de caráter universal" (Brasil, 1997, p. 64). Trata-se de um novo campo de estudo e de ação pedagógica, em que a produção teórica e pedagógica encontra-se em fase inicial.

Observe-se que, por ter caráter pioneiro até mesmo em termos internacionais, a elaboração de propostas de trabalho pedagógico sobre este tema encontra dificuldades. (...) Há um apelo da ONU para que se enviem novas propostas de trabalho neste campo, tal o nível incipiente em que educadores em geral ainda se encontram com relação à temática [da Pluralidade Cultural] (...). No caso do Brasil, algumas iniciativas já tratam ou trataram da temática em projetos específicos e, em geral, pontuais (idem).

O levantamento feito pelo Ministério da Educação, por ocasião da elaboração dos Parâmetros Curriculares Nacionais, indica a existência de estudos acerca de escolas indígenas e de algumas experiências inovadoras vinculadas a movimentos de caráter étnico. Mas pouquíssimo se discutiu sobre uma proposta relativa ao Brasil em sua complexidade cultural, e são raríssimos os estudos que tratam das relações entre crianças e intercâmbio cultural, em seu sentido amplo.

A elaboração de propostas de educação intercultural no Brasil precisa levar em conta a especificidade da formação histórica e social do povo brasileiro.

A formação do povo brasileiro resulta da interação e da miscigenação de diferentes grupos étnicos. O encontro entre diferentes culturas no Brasil foi produzido a partir de grandes fluxos migratórios, ligados principalmente a dois ciclos econômicos anteriores.
Primeiro, no processo de colonização das Américas. A expansão do comércio europeu no século 15 impeliu as classes dominantes da sociedade européia à "descoberta" e à conquista do "Novo Mundo". A ocupação deste território e a implantação do modo de produção capitalista nas Américas se deram com base na exploração da mão-de-obra escrava. De modo particular, os conquistadores portugueses e espanhóis tentaram submeter as populações autóctones das regiões conquistadas. E como estas resistiram à submissão escravista, foram dizimadas ou expulsas para o interior do território. Em seu lugar, foram trazidos à força, pelo comércio de escravos, grandes contingentes de população de origem africana. Assim, os

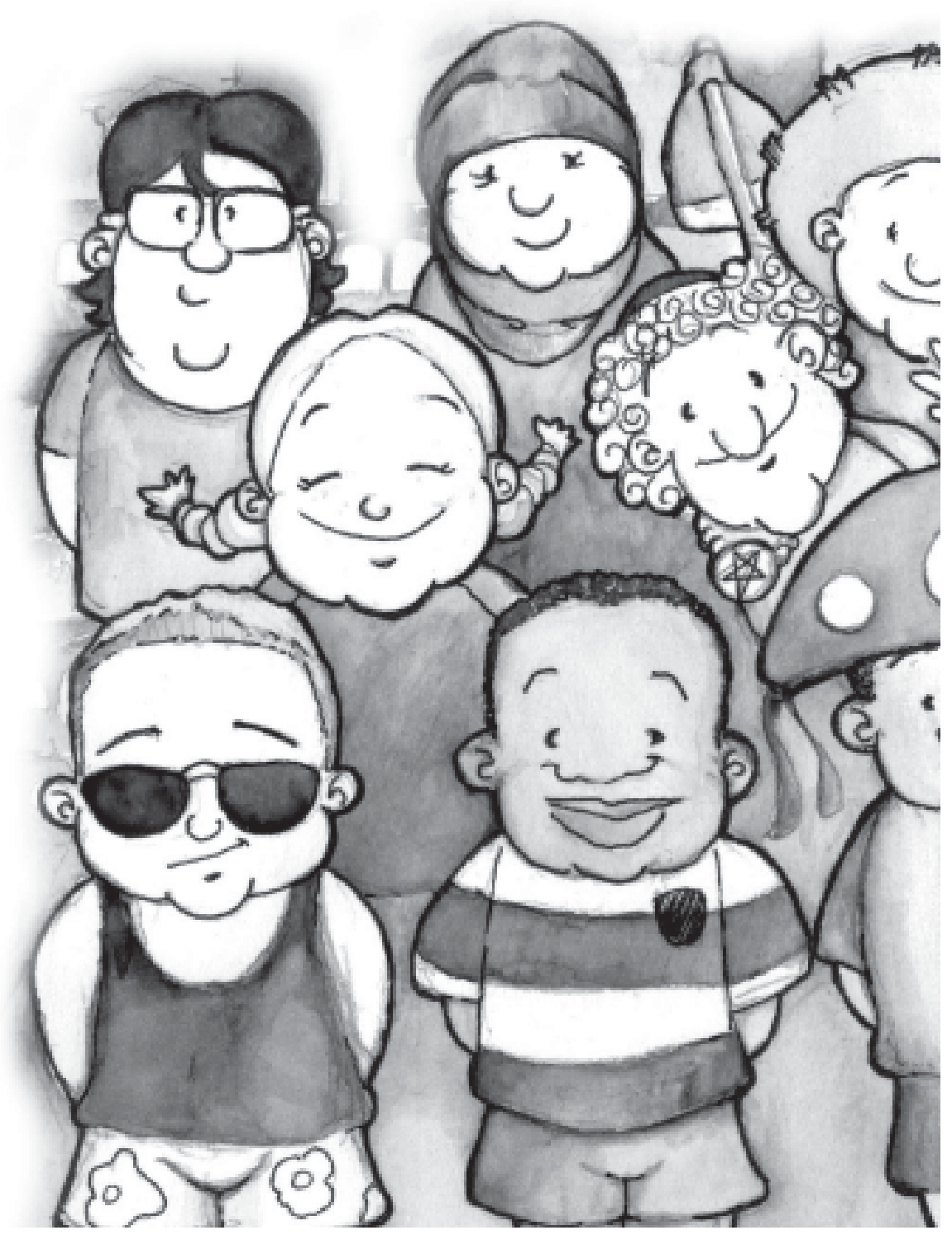


preconceitos racistas, que discriminam os negros e excluem os índios no Brasil e no continente americano, têm suas raízes neste contexto histórico-social da sociedade colonial escravocrata.

O segundo fluxo migratório foi produzido em nível internacional, a partir do século 18. As mudanças das relações de produção, ocorridas com a revolução industrial, tornaram obsoletas e antieconômicas as formas escravistas de exploração do trabalho. As forças econômicas e políticas dominantes das ex-colônias passaram a promover a imigração de trabaIhadores "livres". Estes viviam em condições desfavoráveis nos países europeus industrializados. A perspectiva de uma vida melhor motivou-os a emigrar do

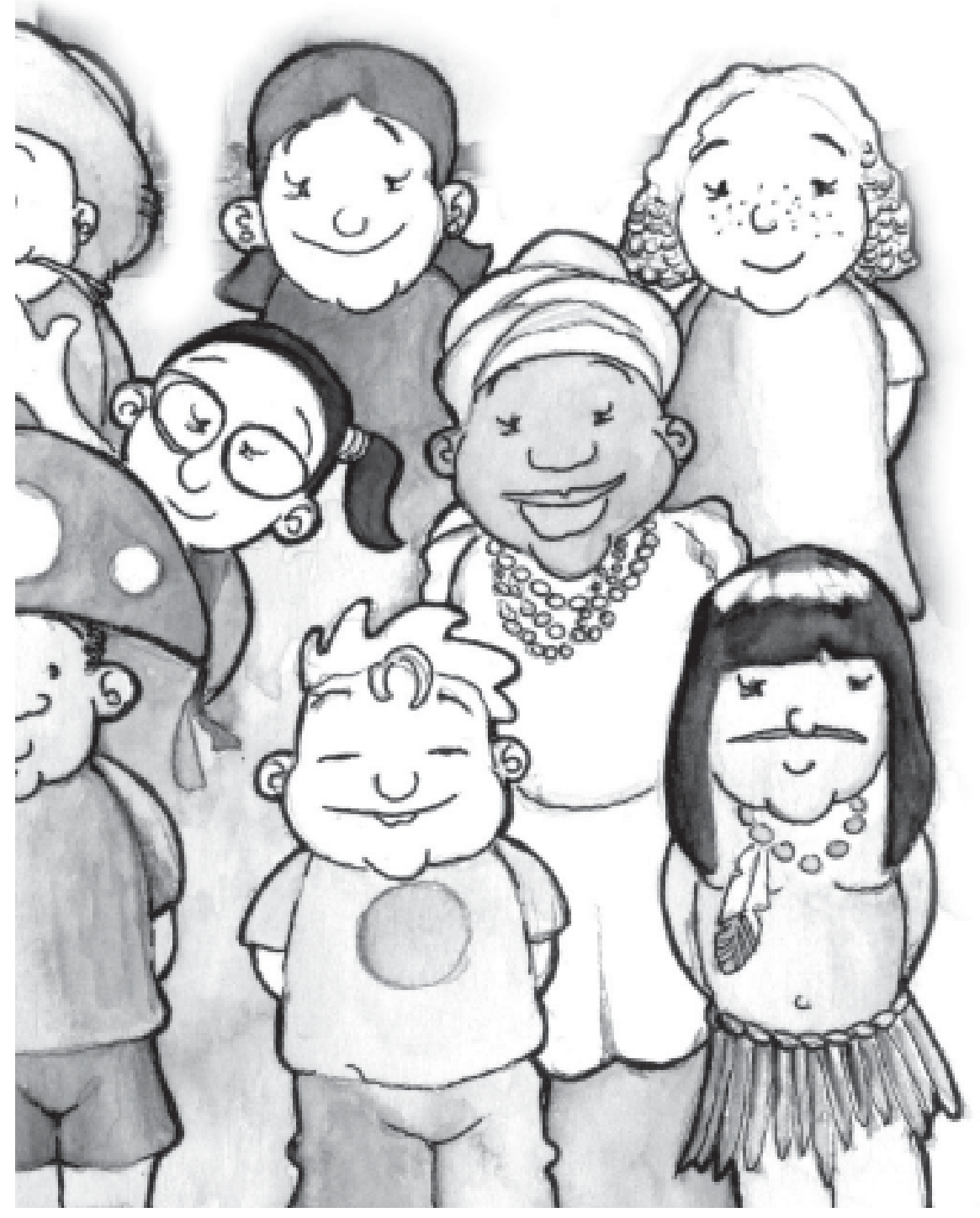

Velho Mundo para as Américas. Sendo mão-de-obra mais qualificada, esses trabalhadores imigrantes sustentaram o novo surto de desenvolvimento econômico capitalista neste continente. O Brasil, assim como outros países das Américas, acolhe entre meados do século 19 e meados do século 20 , um enorme contingente de famílias provenientes da Europa, assim como da Ásia e do Médio Oriente. Estes imigrantes passam a conviver entre si neste novo ambiente. Estabelecem relações com os grupos étnicos que já ocupavam anteriormente o território, os descendentes e mestiços de indígenas, portugueses e africanos. E desenvolvem processos de conflito, de assimilação e de integração interétnica, que deixaram marcas profundas nas atuais relações socioculturais em nosso território.

As relações interculturais e interétnicas no Brasil constituíram-se, pois, a partir de conflitos inerentes aos ciclos econômicos da expansão colonialista, iniciada no século 16, complexificando-se a partir das revoluções industriais do século 19. Nestes dois momentos históricos, ocorreu grande deslocamento populacional das "metrópoles" européias na direção de suas colônias das Américas.

Hoje, porém, os fluxos migratórios no mundo assumiram outras direções. Particularmente após a Segunda Guerra Mundial, muitos países da Europa acolheram grande contingente de imigrantes provenientes de suas ex-colônias. Estes foram assimilados em função da reconstrução econômica européia. Atualmente, a globalização econômica, que flexibilizou as fronteiras nacionais, intensifica ainda mais os processos migratórios na direção dos países mais ricos. Mas, também nestes países, as crises econômicas agravam o desemprego e reduzem a disponibilidade de recursos econômicos. E, no contexto de oportunidades restritas, as lutas pela defesa de privilégios ou pelo reconhecimento de direitos aos excluídos agravam os conflitos entre os diferentes grupos em disputa. É assim que, principalmente nos países mais industrializados do Hemisfério Norte, emerge o debate e a formulação de políticas relativas às relações multiculturais. Pois nestes países os recentes fluxos de imigrantes provenientes de países mais pobres do Hemisfério Sul têm acirrado conflitos entre os estrangeiros e 
as populações autóctones. Este fenômeno é diferente do que acontece no Brasil e na América Latina: aqui os conflitos de natureza étnica e cultural são aparentemente menos explícitos, porque sedimentados em momentos históricos anteriores.

No contexto europeu, portanto, os estudos e as propostas de educação multicultural e intercultural têm sido elaborados em estreita relação com a presença de imigrantes. Estes, em quantidade cada vez mais maciça desde os últimos cinqüenta anos, buscam inserir-se no mercado de trabalho e na vida social de vários países desenvolvidos. As propostas de educação intercultural foram inicialmente elaboradas para responder à emergente necessidade de acolher os estrangeiros e, particularmente, os filhos dos imigrantes na escola. Com isso, buscavam promover a superação de velhos e novos racismos, favorecendo a integração entre pessoas de culturas diferentes que se confrontam no cotidiano.

Estimulado, entretanto, por diferentes movimentos sociais, o debate europeu sobre a "intercultura" envolveu campos de reflexão e de intervenção que ultrapassaram progressivamente o caráter emergencial do problema de inserção dos migrantes. Foi necessário esclarecer como se dão os processos de formação da identidade pessoal e coletiva. Foi preciso entender o significado e o valor das diferenças, pelas quais se identificam os grupos sociais. Foi preciso estudar a configuração e a função que assume hoje o sentido de coletividade em sociedades complexas. Nas sociedades complexas - que se caracterizam pela relação entre ambientes culturais plurais e indefinidos - os indivíduos interiorizam na vida cotidiana formas e conteúdos culturais muito diferentes, ou mesmo antagônicos entre si. De acordo com sua posição social, as pessoas relacionam-se com uma grande variedade de canais de comunicação e de experiências. $\mathrm{E}$ elaboram no decurso da própria vida sínteses de modelos, freqüentemente contraditórios. Assim, na prática pedagógica, aparece como principal desafio a necessidade de elaborar a multiplicidade e a contraditoriedade de modelos culturais que interferem na formação da visão de mundo dos educandos. Trata-se também de compreender as relações que tal visão estabelece com os modelos (de conhecimento, de avaliação, de comportamento) transmitidos através de situações educativas, particularmente na escola. $\mathrm{O}$ foco central da prática educativa deixa de ser a transmissão de uma cultura homogênea e coesa. A preocupação fundamental da educação passa a ser a elaboração da diversidade de modelos culturais que interagem na formação dos educandos. Tal deslocamento de perspectiva legitima as culturas de origem de cada indivíduo e coloca em xeque a coesão da cultura hegemônica. $E$ este fato traz conseqüências para a elaboração dos métodos e das técnicas de ação pedagógica e de transmissão da cultura oficial.

$\mathrm{Na}$ realidade brasileira, a dimensão intercultural se reveste de significados específicos. Colonialismos e migrações, dominações e convivências têm induzido profundos processos de aculturação: fusões sincréticas e violentas, perdas de identidade cultural encontram-se na própria formação da sociedade brasileira. Numerosos pesquisadores, particularmente das áreas de história e antropologia, procuraram reconstruir os desdobramentos e os multiformes resultados dos contatos - espontâneos ou forçados - que se verificaram entre os diversos grupos. Verifica-se que o encontro/confronto entre culturas diferentes configura as próprias raízes da formação social brasileira e que os processos de integração historicamente aconteceram com profundidade. Por isso, o enfoque intercultural sobre esta realidade precisa ser colocado em um quadro de referência mais geral. A orientação das formas de relação entre grupos étnicos diferentes e as propostas de enfrentamento dos conflitos nelas emergentes vai muito além da atenção ao acolhimento dos estrangeiros, tal como a educação intercultural havia inicialmente priorizado na Europa. 
Também, no Brasil, verificam-se graves fenômenos de racismo, de discriminação étnica e social, de fechamento ao diferente. Mas coloca-se em primeiro plano a importância de conhecer - com a finalidade de orientar a prática pedagógica - os complexos itinerários de formação e produção cultural que percorrem contextos já fortemente miscigenados. De modo particular, os contextos que se caracterizam por graves problemas sociais. Tratase de problematizar a imagem de "democracia racial" no Brasil ou de "melting pot" (caldeirão étnico). Tais interpretações a respeito da formação do povo brasileiro acobertam grande parte da conflitividade das relações interculturais em nosso contexto. E, sobretudo, enfraquecem o enorme potencial que pode advir do confronto e da interação crítica entre diferentes grupos culturais. Esta perspectiva problematizadora da dimensão intercultural pode oferecer aos agentes - institucionais ou populares - instrumentos indispensáveis à sua prática educativa. De modo particular, proporcionar meios para promover a formação da autoconsciência - e, portanto, de "presença" e ação - em sujeitos que vivem em ambientes marginalizados (rurais e urbanos). A perspectiva intercultural da educação pode, ainda, estimular os movimentos sociais a focalizar, na própria reflexão e na própria prática, a dialética identidade/alteridade. Ou seja, estimular a consciência das diferenças e das relações entre os agentes e os pontos de vis-

ta que nele se articulam. Assim, os movimentos sociais

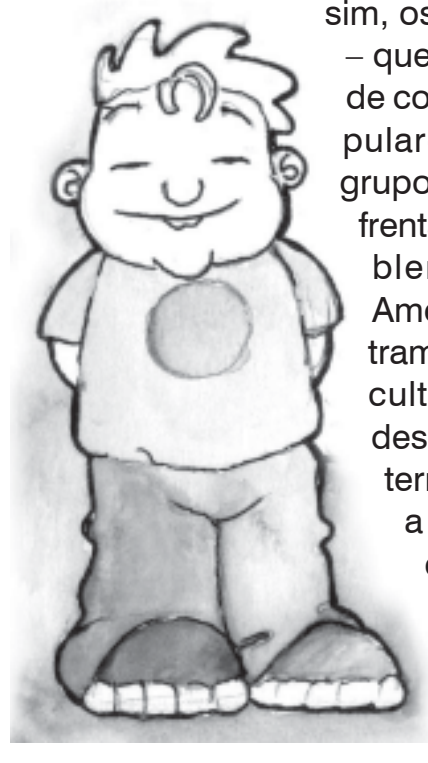
- que exprimem a vitalidade com que as classes populares (assim como os grupos que as apóiam) enfrentam os profundos problemas estruturais na América Latina - encontram na perspectiva intercultural estímulos para desenvolver a coesão interna e a solidariedade, a capacidade de distinção e de luta, ao lado da possibilidade de integração emancipatória com outros grupos sociais.

\section{Epistemologia e complexidade}

Reconhecer e assumir a multiplicidade de práticas culturais, desenvolvidas pela interação de diferentes sujeitos nas relações sociais e nos processos educativos, implica percebê-los e orientá-los segundo uma lógica (ou paradigma epistemológico) capaz de compreender a relação da unidade do conjunto com a diversidade de elementos que o constituem.

É este o grande desafio que se coloca hoje com o conceito de transversalidade e a proposta de desenvolver os temas transversais no currículo escolar. Eles

remetem inexoravelmente à complexificação e à globalização do currículo (...) e uma maneira diferente de conceber a função de um novo paradigma, que temos chamado de paradigma sistêmico (chamado também de global, ecológico, complexo), o qual já está começando a afirmar-se, em todos os ramos do saber e da cultura, como necessidade e como reação diante das insuficiências do paradigma mecanicista (chamado também de analítico, cartesiano, simplificador) o qual tem dominado nossa cultura há séculos. O conflito aparece quando os temas transversais exigem um planejamento sistêmico, e o restante do currículo e a organização escolar persistem em seu planejamento analítico. Essa dupla linguagem se resolve infalivelmente a favor do paradigma atual, da ordem estabelecida, que também é o que sintoniza com a cultura do professorado, formado inicial e permanentemente por estas clássicas coordenadas (Yus Ramos, 1998, p. 10).

Estando no nível do paradigma mecanicista, as reformas curriculares parecem enfrentar dois interesses opostos:

por um lado interessa-nos indivíduos que assimilem uma cultura que se revelou imprescindível para o desenvolvimento (cultura científico-tecnológica), mas, por outro, também nos interessa deixar claro que somos sensíveis aos problemas que esse desenvolvimento provoca no tecido social e, por isso, também nos interessam indivíduos solidários, tolerantes, que saibam proteger sua saúde, a natureza, etc. (idem, p. 10-11).

Desenvolvimento científico-tecnolgico e desenvolvimento humano-ecológico 
aparecem como dois pólos opostos entre os quais é preciso optar. Mas será mesmo?

Estamos, antes de tudo, diante de um problema de caráter epistemológico. Epistemologia, em sentido amplo, significa um conjunto de premissas que sustentam nossos modos de fazer distinções, de segmentar os eventos, de dar sentido ao mundo (Bateson, 1976, 1986). Os tipos de distinção que são normalmente assumidos em nossas escolas são baseados na oposição: ou/ou. Esta forma de pensar nos leva fatalmente a escolher um pólo, excluindo ou submetendo todos os outros. Mas numa outra perspectiva epistemológica, a complexa, são propostas

\begin{abstract}
premissas diferentes para nossos sistemas de distinção: uma epistemologia da conexão: e/e. As oposições não devem ser (ingenuamente) eliminadas, mas é indispensável descobrir a estrutura que possa conectá-las, o contexto comunicativo que possa coligá-las. (...) As conexões, dentro de um novo contexto, permitem às oposições de se diluírem; e isto não tanto por que as contradições desaparecem, mas porque se produzem mudanças, evoluções, que envolvem todos os membros em oposição (Severi, Zanelli, 1990, p. 31-32).
\end{abstract}

Neste sentido "um projeto educativo complexo deve poder considerar como correlacionadas (pensar contemporaneamente) tanto a diferenciação das identidades quanto as estruturas de conexão (os contextos comunicativos)" (Idem, p. 39).

Trata-se, pois, de complexidades que se tecem juntas, desafiando-nos a trabaIhar com a incerteza e com um pensamento multidimensional, um pensamento baseado, segundo Edgar Morin (1985, p. 57), na dialógica, que "significa que duas lógicas, duas 'naturezas', dois princípios são coligados em uma unidade sem que com isto a dualidade se dissolva na unidade".

Assim, o método da complexidade nos orienta a pensar sem nunca fechar os conceitos, a quebrar as esferas fechadas, a restabelecer as articulações entre o que se encontra dividido, a nos esforçar para compreender a multidimensionalidade, a pensar com a singularidade, com a localidade, com a temporalidade, a jamais esquecer as totalidades integradoras. É a tensão na direção do saber total, e ao mesmo tempo a consciência contrária do fato que, como disse Adorno, "a totalidade é a não-verdade". A totalidade é ao mesmo tempo verdade e não-verdade, e a complexidade reside justamente nisto: na conjunção de conceitos que se combatem reciprocamente (idem, p. 59-60).

Nesta perspectiva, as pesquisas de Gregory Bateson apresentam uma contribuição importante com a noção de ecologia da mente, um modo novo de pensar "interdisciplinar, mas não no sentido simples e ordinário de consentir uma troca de informações através dos confins das disciplinas, mas de permitir a descoberta de estruturas comuns a muitas disciplinas" (Donaldson, 1997, p. 18).

Amente, para Bateson (1986, p. 99-100), significa um agregado de partes ou componentes, cuja interação é acionada por idéias. Mas as idéias são algo de "muito mais amplo e formal do que são consideradas tradicionalmente": uma idéia é "uma diferença que produz uma diferença" que se propaga em um circuito. Assim, os problemas de articulação das idéias não são de caráter lógico, mas ecológico.

\section{Paradigma da complexidade e cientificidade}

Ao definir o conceito de mente, Bateson se aventurava a retomar temas como intimidade, sagrado, empatia, holismo, metáfora. Ele tinha consciência de que estava trilhando caminhos já percorridos por uma multidão, em meio à qual muitos tentavam uma fuga da ciência (considerada - talvez com razão - reducionista e finalista) na direção de um holismo mistificante. Ele conviveu em seus últimos anos com grupos "alternativos". Estes o respeitavam, contudo, consideravam-se como seus únicos verdadeiros intérpretes. Mas não percebiam que Bateson era muito diferente deles e que a ciência na qual ele trabalhava poderia ser uma alternativa também para eles. A renúncia à ciência é para Bateson uma grande tolice (cf. Conserva, 1998).

A respeito desta questão, Tullio Seppilli (1996, p. 20) nos alerta - ao analisar a cientificidade da medicina ocidental - que os limites de tal área de conhecimento 
não derivam de seu caráter científico mas, ao contrário, da insuficiente cientificidade de seu atual paradigma, ou seja, justamente de seu fechamento no enfoque biológico e desconsideração das dimensões da subjetividade e em geral do social (...) e que, aliás, é preciso superar tais limites e tais sinais de crise recusando qualquer contraposição esquemática e abstrata entre a atenção às determinações sociais e a atenção aos processos biológicos e, principalmente, recusando qualquer tentação reacionária de fuga para o irracionalismo e para a mera contraposição entre as medicinas 'alternativas' e a medicina 'científica'.

Neste sentido, numa tentativa de generalização destas considerações para outros campos da ciência, podemos pressupor que, para ser legitimamente científico, o saber deve incorporar - em um horizonte unitário e coerente - as diferentes formas de conhecimento e as diferentes dimensões da realidade natural, biológica, subjetiva, social, cultural.

Em Mente e natureza, Bateson propôs "uma metaciência indivisível e integrada, cujo objeto seja o mundo da evolução, do pensamento, da adaptação, da embriologia e da genética: a ciência da mente na acepção mais vasta do termo". O que ele queria explorar era "aquele conhecimento mais amplo que é o cimento que mantém unido ... o mundo biológico global em que vivemos e em que se encontra o nosso ser" (Donaldson, 1997, p. 18).

O método desta metaciência é a "descrição dupla e múltipla", ou seja, uma justaposição de processos mentais (agregados de idéias) capaz de desvelar tanto as estruturas subjacentes e a economia da estruturação nelas encarnada, quanto às complexas riquezas e ao aumento de compreensão promovidos pela combinação entre elas. É exatamente este método que possibilita a elaboração de um conhecimento de "segundo nível" (Bateson, 1976 , p. 319-328), ou seja, a compreensão do contexto que, construído pelos próprios sujeitos em interação, configura os significados de seus atos e relações. "Estou dizendo que existe um aprendizado do contexto (...). Estou dizendo também que esse aprendizado do contexto resulta de uma espécie de descrição dupla que acompanha o relacionamento e a interação" (Bateson, 1986, p. 142). Às mudanças nas estruturas de contextos e processos "mentais", Bateson (1976, p. 319) chama de aprendizagem de segundo nível: "por exemplo, uma mudança corretiva no conjunto de alternativas frente aos quais se realiza a escolha, ou a mudança na segmentação da seqüência das experiências".

\section{Implicações pedagógicas da complexidade}

A educação intercultural, na perspectiva epistemológica da complexidade, pode ser entendida como processos de aprendizagem de segundo nível, uma vez que promovem o desenvolvimento de contextos educativos que permitem a articulação entre diferentes contextos subjetivos, sociais e culturais.

Nesta direção, a reconhecida contribuição de Gregory Bateson para a reformulação da concepção de pesquisa antropológica (que passou a ser assumida não mais como um processo de conhecimento objetivo de outras culturas, mas como o estabelecimento de um contexto relacional novo entre sujeitos de contextos socioculturais diferentes) pode ser muito fecunda para se redimensionar criticamente a relação educador/educando, particularmente quando estes estabelecem conexões interativas com outros sujeitos inseridos em contextos educativos e culturais diferentes.

Tais questões apontam como horizonte da pesquisa a formulação de princípios que sirvam de referência para a compreensão e construção de processos educativos em que diferentes sujeitos constituem sua identidade, elaborando autonomia e consciência crítica, na relação de reciprocidade (cooperativa e conflitual) com outros sujeitos, criando, sustentando e modificando contextos significantes, que interagem dinamicamente com outros contextos, criando, sustentando e modificando metacontextos, na direção de uma "ecologia da mente".

Ao procurar elaborar uma compreensão dos processos e contextos educativos que permitem a articulação entre diferentes contextos culturais, assumimos como referência norteadora o entendimento de que o processo educativo se desenvolve como 
um sistema mental, composto por múltiplos elementos, cuja interação é acionada por diferenças que, ativadas por energia colateral, desencadeiam versões codificadas e circulam em cadeias de determinação complexas, que se articulam em uma hierarquia de tipos lógicos inerente ao próprio processo de transformações (cf. Bateson, 1986, p. 99-100).

Tal concepção de educação traz como corolário a necessidade de se repensar e ressignificar a concepção de educador. Pois, se o processo educativo consiste na criação e no desenvolvimento de contextos educativos, e não simplesmente na transmissão e assimilação disciplinar de informações especializadas, ao educador compete a tarefa de propor estímulos (energia colateral) que ativem as diferenças entre os sujeitos e entre seus contextos (histórias, culturas, organizações sociais...) de modo a desencadear a elaboração e circulação de informações (versões codificadas das diferenças e das transformações) que se articulem em diferentes níveis de organização (seja em âmbito subjetivo, intersubjetivo, coletivo, seja em níveis lógicos diferentes). Educador, neste sentido, é propriamente um sujeito que se insere num processo educativo, e interage com outros sujeitos dedicando particular atenção às relações e aos contextos que vão se criando, de modo a contribuir para a explicitação e elaboração dos sentidos (percepção, significado e direção) que os sujeitos em relação constroem e reconstroem. Nestes contextos, o currículo e a programação didática, mais do que um caráter lógico, terão uma função ecológica, ou seja, sua tarefa não será meramente a de configurar um referencial teórico para o repasse hierárquico e progressivo de informações, mas terá a tarefa de prever e de preparar recursos capazes de ativar a elaboração e circulação de informações entre sujeitos, de modo que se auto-organizem com relação à reciprocidade entre si e com o próprio ambiente.

\section{Referências bibliográficas}

BATESON, Gregory. Mente e natureza : a unidade necessária. Trad. Claudia Gerpe. Rio de Janeiro : Francisco Alves, 1986. Tradução de: Mind and nature: a necessary unity, 1979.

. Una sacra unità. Altri passi verso un'ecologia della mente. Trad. Giuseppe Longo. Milano : Adelphi, 1997. Tradução de: A sacred unity. Further steps to an ecology of mind, 1991.

. Verso un'ecologia della mente. Trad. Giuseppe Longo. Milano : Adelphi, 1976. Tradução de: Steps to an ecology of mind, 1972.

BONACICH, E., MODELL, J. The economic basis for ethnic solidarity small business in the japanese-american community. Berkeley : University of California, 1980.

BONFIGLI, Gabriele, SPADARO, Marina. Intercultura e cooperazione. Cooperazione Educativa, n. 1, p. 19-22, 1995.

BRASIL. Ministério da Educação e Cultura. Secretaria de Educação Fundamental. Parâmetros curriculares nacionais : pluralidade cultural e orientação sexual. Brasília: MEC/SEF, 1997. 164 p.

BUSQUETS, Maria Dolores et al. Temas transversais em educação. São Paulo : Ática, 1998.

CONSERVA, Rosalba. Relazione introdutiva. In: GIORNATE DI STUDIO SU GREGORY BATESON, 13-14 fev. 1998, Roma. La natura dell'apprendere e del pensare : "... gli uomini sono erba". Roma, 1998. (Conferência de abertura). 
DONALDSON, Rodney A. Introduzione. In: BATESON, Gregory. Una sacra unità. Altri passi verso un'ecologia della mente. Trad. Giuseppe Longo. Milano : Adelphi, 1997. (Tradução de: A sacred unity. Further steps to an ecology of mind, 1991).

FLEURI, Reinaldo Matias (Org.). Educação popular e complexidade. In: COSTA, M. V. Educação popular hoje. São Paulo : Loyola, 1998a. p. 99-122. Intercultura e movimentos sociais. Florianópolis : Mover/NUP, 1998b. 216 p.

GALLINO, L. Identità, identificazione. Laboratorio Politico, v. 2, p. 145-157, sett./dic. 1982.

MORIN, Edgar. Le vie della complessità. In: BOCCHI, G., CERUTI, M. La sfida della complessità. Milano : Feltrinelli, 1985. p. 49-60.

NANNI, Antonio. L'educazione interculturale oggi in Italia. Brescia : EMI, 1998.

SCHERER-WARREN, Ilse. Movimentos sociais e a dimensão intercultural. In: FLEURI, R. M. (Org.). Intercultura e movimentos sociais. Florianópolis : Mover/NUP, 1998. p. 31-32.

SEPPILLI, Tullio. Antropologia medica : fondamenti per una strategia. Rivista della Società Italiana di Antropologia Medica, Perugia, v. 1/2, p. 7-22, ott. 1996.

SEVERI, Vittorio, ZANELLI, Paolo. Educazione, complessità e autonomia dei bambini. Firenze : Nuova Italia, 1990.

UNESCO. Declaração sobre raça e sobre preconceitos raciais. [S.I. : s.n], 1978 apud NANNI, Antonio. L'educazione interculturale oggi in Italia. Brescia : EMI, 1998.

YUS RAMOS, Rafael. Temas transversais : a escola da ultramodernidade. Pátio, revista pedagógica, v. 2, n. 5, p. 8-11, maio/jul. 1998.

Recebido em 10 de setembro de 1999.

Reinaldo Matias Fleuri, doutor em Filosofia e História da Educação pela Universidade Estadual de Campinas (Unicamp), é professor titular do Departamento de Estudos Especializados em Educação, no Centro de Ciências da Educação, da Universidade Federal de Santa Catarina (UFSC).

\section{Abstract}

The intercultural education, in the context of social struggles against the crescent processes of social exclusion inherent to the economical globalization, proposes the development of strategies that promote the construction of particular identities and the recognizing of the differences, at the same time in which they support the critical and solidaristic inter-relation among different groups. The article presents an operational concept of the intercultural education, elaborated from studies developed in Europe. It verifies the need to put back the proposal of intercultural education, considering the specificity on the formation of the cultural identities and of the processes of inter-ethnical integration in Brazil. And it proposes an epistemological perspective of the complexity, based on Gregory Bateson's premises, to understand and to guide the development of educational contexts that promote the articulation among different subjective, social and cultural contexts.

Keywords: intercultural education; cultural plurality; identity; transversal; epistemology; complexity. 